estimation of an array of blood and urine constituents, can be described as "uncooperative."-I am, etc.,

Norwich

D. E. L. Howes

\section{Carbenoxolone Sodium and Deglycyrrhizinated Liquorice in Gastric Ulcer}

SIR-Carbenoxolone sodium has not been used for over 10 years and has been the subject of most intensive and rigarous trials in many countries. It has been shown beyond doubt to aid the healing of gastric ulcer and will enable ulcers to heal with ambulatory treatment at the same rate as they would if the patient went to bed. It does so by stimulating the production of mucus, by lengthening the life cycle of the gastric epithelial cells, and by minimizing the back-diffusion of hydrogen ions under the influence of various adverse factors, including the presence of bile. Carbenoxolone sodium is a potent drug and, in common with some other potent drugs, has some side effects, which in practice can be easily controlled.

There have been claims recently that deglycyrrhizinated liquorice, which is free from side effects, is equally beneficial. To have a potent treatment entirely free from side effects would be a most acceptable situation. Unfortunately, the evidence for this claim is still based on small numbers and must be viewed with considerable caution. When extra help is particularly needed carbenoxolone sodium should be used, prescribing it with the same care and discretion as is normally used when administering antibiotics and corticosteroids.-I am, etc.,

Central Middlesex Hospital,
London, N.W.10

F. AVERY JONES

Higher Specialist Training in General

SIR,-The Joint Committee on Higher Surgical Training, on the recommendation of the Specialist Advisory Committee in General Surgery, has now approved 182 programmes of higher specialist training in general surgery, in addition to those approved in the other surgical specialties, details of which will shortly be available for publication. Programmes are designed for three or four years and involve university and district general hospita's and are held by senior registrars or lecturers.

The joint committee also recognizes the high quality of training which many registrars are receiving in the years prior to entering the senior registrar grade and proposes to acknowledge this by aoreeing to give retrospective approval to certain appointments in the registrar grade which can provide higher specialist training for periods of one year. Trainees entering on programmes of higher specialist training and the senior regjstrar or lecturer grade will be able to count such a period of training towards their total programme for certification. These affiliated posts are almost a'l in district general hospitals. Trainees who have obtained a senior registrar or equivalent post in an approved programme should apply now for enrolment with the Specialist Advisory Committee.

The Specialist Advisory Committee in General Surgery is also aware of the importance of registrar appointments suitable for basic training in surgery and wishes to emphasize that the selection of some posts for higher specialist training in no way detracts from the importance and value of posts suitable for trainees preparing for the F.R.C.S. examination. With this in view, balanced programmes of surgical training in each region should have an adequate number of rotating registrar posts for the essential basic training in general surgery as well as posts for higher specialist training. These registrar posts are of considerable importance and will be filled by trainees preparing for higher training in each of the recognized surgical specialties. -I am, etc.

\section{R. S. JOHNSON-GILBERT Secretary,
Joint Committee on Higher
Surgical Training} Royal College of Surgeons of England,

London, $\mathbf{W} . \mathrm{C} .2$

\section{Side Effects of the Pill}

SIR,-It was suggested by Dr. D. A. Varvel (23 December 1972, p. 729) that complete loss of libido is a common side effect of oral contraceptives. A possible reason was discussed by Flt. Lt. D. J. S. Triplett (13 January, p. 111).

At Sussex family planning clinics the frequency and severity of this problem have been assessed. In the past three months all women on oral contraceptives have been included in this survey who had had sexual experience before starting oral contraception. Age, marital status, parity, and time on oral contraceptives were recorded. Each woman was asked: (1)-Would another pregnancy at this time be (a) disastrous; (b) inconvenient; or (c) acceptable? (2)-In comparison with previous experience, is your interest in and enjoyment of sexual relations while on oral contraceptives (a) increased; (b) the same; (c) less; or (d) severely decreased? The results are shown in table I.

TABLE I-Effects of Oral Contraception on Iibido in Married and Single Women

\begin{tabular}{l|c|c|c|c|c}
\hline & Better & Same & Worse & $\begin{array}{c}\text { Much } \\
\text { Worse }\end{array}$ & Total \\
\hline $\begin{array}{l}\text { Married } \\
\text { Single }\end{array}$ & $\begin{array}{c}47 \\
58\end{array}$ & $\begin{array}{c}39 \\
25\end{array}$ & $\begin{array}{r}20 \\
7\end{array}$ & $\begin{array}{c}2 \\
0\end{array}$ & $\begin{array}{c}108 \\
90\end{array}$
\end{tabular}

Thus $64 \%$ of single women and $43.5 \%$ of married women claimed an immrovemen in libido, while $8 \%$ of single and $20 \%$ of married women had reduced or severely reduced libido. In each case the difference between single and married women is significant $(P<0.05)$. Of the seven single women adversely affected, five had been living in a marriage-like situation for two or more years. The single women were on average younger than the married, and a smaller number had taken oral contraceptives for more than three years. No correlation was found between reduced libido and parity or time on oral contraceptives.

Dr. M. J. V. Bull (3 Februarv, p. 295) suggested that oral contraceptives are more likely to denress sexual drive in older women. Table II shows that $25 \%$ of women over 25 complained of reduced libido compared with 9\% under 26. However, most single girls, in whom the complaint is less frequent, were under 25.

TABLB II-Effect of Age on Change in Libido in Married and Single Women

\begin{tabular}{l|c|c|c|c|c}
\hline & $\begin{array}{c}20 \text { or } \\
\text { less }\end{array}$ & $21-25$ & $26-30$ & $31-35$ & $\begin{array}{c}\text { over } \\
35\end{array}$ \\
\cline { 2 - 6 } & 2 & 40 & 25 & 6 & 13 \\
\hline $\begin{array}{l}\text { Same or better } \\
\begin{array}{l}\text { Worse or much } \\
\text { worse }\end{array}\end{array}$ & 3 & 4 & 10 & 3 & 2 \\
\hline $\begin{array}{l}\text { Same or better } \\
\begin{array}{l}\text { Worse or much } \\
\text { worse }\end{array}\end{array}$ & 45 & 31 & 6 & 1 & 0 \\
\hline
\end{tabular}

Considering married women only, there is no significant difference in the proportions adversely affected in the age groups under 26 , 26-30, and over 30 . This suggests that the apparent freedom of single girls from this side effect of oral contraceptives is not due simply to their relative youth.

Twelve out of 42 married women for whom pregnancy would be disastrous had reduced libido compared with two out of 22 for whom it would be acceptable. The difference is suggestive but just fails to reach the $5 \%$ level of significance. If this finding is confirmed, the implications would be interesting.

Only two patients with loss of libido described it as severe, amounting to an active distaste for sex. The other 27, when asked to amplify the complaint, used such phrases. as "loss of enthusiasm" and "boredom with their partner," but the majority experienced normal arousal. Many hesitated to attribute the symptom to oral contraceptives. Fatigue, due to work and young children, and financial worry combine to cause anxiety and depression, resulting in reduced sexual interest, which may be blamed on oral contraceptives. Indeed it is as useful a scapegoat as the menopause. Single girls, free of the worries of the young married women, were remarkably free of this complaint, and, released from the risk of pregnancy, the majority claimed increased libido on oral contraceptives.

These findings do not support the idea of Flt. Lt. Triplett that the impossibility of conception reduces sexual drive, though this may be true for those few women in the survey who volunteered that they "missed the element of risk." We d'd not investigate the connexion berween loss of libido and freauency of orgasm as suggested by Flt. Lt. Triplett. However, this interesting question could easily be decided by a survey similar to ours.

In summary, about $14.5 \%$ of all women on oral contraceptives are likely to complain of some loss of sexual drive at any one time, but only a small percentage will need to discontinue for this reason. The frequency of the problem is less in single girls than in married women, and this is not onlv due to age differences. When new contraceptives are tested, the frequency of libido problems in university and college clinics is likelv to differ from that in clinics catering mainly for marred women. The use of a simnle olus or minus score in investigating loss of libido results in the concealment of interesting information. -We are, etc.,

David M. HaLl Reigate, Surrey 